\title{
Feasibility of lung transplantation from donors mechanically ventilated for prolonged periods
}

\author{
Seiichiro Sugimoto ${ }^{1} \cdot$ Takeshi Kurosaki $^{2} \cdot$ Shinji Otani $^{2} \cdot$ Shin Tanaka $^{1} \cdot$ Yukiko Hikasa $^{3} \cdot$ Masaomi Yamane $^{1}$. \\ Shinichi Toyooka ${ }^{1} \cdot$ Motomu Kobayashi $^{3} \cdot$ Takahiro Oto $^{2}$
}

Received: 23 July 2018 / Accepted: 27 September 2018 / Published online: 27 October 2018

(c) Springer Nature Singapore Pte Ltd. 2018

\begin{abstract}
Purpose When patients are mechanically ventilated for more than 5 days, they are usually declined as donors for lung transplantation (LTx); thus, the long-term outcomes of LTx from such donors remain unclear. We investigated the feasibility of LTx from donors that had been mechanically ventilated for prolonged periods.

Methods The subjects of this retrospective comparative investigation were 31 recipients of LTx from donors who had been mechanically ventilated for $<5$ days (short-term group) and 50 recipients of LTx from donors who had been mechanically ventilated for $\geq 5$ days (long-term group).

Results The median duration of donor mechanical ventilation was 3 days in the short-term group and 8.5 days in the longterm group. However, other than the difference in the duration of donor ventilation, there were no significant differences in the clinical characteristics of the donors or recipients between the groups. The overall survival rate after LTx was comparable between the long-term group and short-term group (5-year survival rate, $66.6 \%$ vs. $75.2 \%$ ).

Conclusion The potential inclusion of donors who have been on mechanical ventilation for more than 5 days could be a feasible strategy to alleviate donor organ shortage.
\end{abstract}

Keywords Lung transplantation $\cdot$ Brain-dead donor $\cdot$ Mechanical ventilation $\cdot$ Extended-criteria donor $\cdot$ Marginal donor

\section{Introduction}

Extended-criteria donor (ECD) lungs from brain-dead donors have been used widely for lung transplantation (LTx) to help resolve the problem of donor shortage [1]. Among ECDs, those supported by mechanical ventilation for prolonged periods are generally considered as marginal, because prolonged mechanical ventilation in brain-dead

This paper was presented at the 38th annual meeting and scientific sessions of the International Society for Heart and Lung Transplantation, Nice, France, April 2018.

Seiichiro Sugimoto

sugimo-s@cc.okayama-u.ac.jp

1 Department of General Thoracic Surgery, Okayama University Hospital, 2-5-1 Shikata-cho, Kita-ku, Okayama 700-8558, Japan

2 Department of Organ Transplant Center, Okayama University Hospital, Okayama, Japan

3 Department of Anesthesiology and Resuscitology, Okayama University Hospital, Okayama, Japan donors can impair the lungs by causing neurogenic lung edema, atelectasis, and/or ventilator-associated pneumonia [2, 3]. In fact, mechanical ventilation for more than $48 \mathrm{~h}$ was found to be correlated with pneumonia in donor lungs [4]. Accordingly, subjects mechanically ventilated for more than 5 days are usually declined as donors for LTx; however, no definitive data on the long-term outcomes of LTx from such donors have been published to validate this generally accepted practice $[2,3]$. Although we recently reported a negative impact of prolonged mechanical ventilation on the early outcomes after LTx [5], such as primary graft dysfunction (PGD), we still consider that the inclusion of subjects mechanically ventilated for prolonged periods as LTx donors could be an effective strategy to expand the donor pool for LTx. This retrospective study compares the outcomes of LTx from donors mechanically ventilated for short periods $(<5$ days) with those from donors mechanically ventilated for prolonged periods ( $\geq 5$ days), and investigates the feasibility of LTx from donors mechanically ventilated for prolonged periods. 


\section{Methods}

\section{Patients}

We reviewed, retrospectively, the outcomes of LTx from brain-dead donors, for various end-stage lung diseases at Okayama University Hospital. Between January, 2001 and May, 2017, we performed 81 LTxs from brain-dead donors. LTxs from donors who had been on mechanical ventilation for $<5$ days were designated as the short-term (ST) group $(n=31)$, and LTxs from donors who had been on mechanical ventilation for $\geq 5$ days were designated as the longterm (LT) group $(n=50)$. We assessed the donor and recipient characteristics, as well as the postoperative outcomes. The donor lungs were assigned lung donor scores based on the following five variables proposed by Oto et al.: age, smoking history, chest X-ray findings, presence/absence of secretions, and the ratio of the arterial oxygen tension to the inspired oxygen fraction $\left(\mathrm{PaO}_{2} / \mathrm{FiO}_{2}\right)$ [6]. According to this scoring system, the former four variables are assigned scores of 0 and 3 , and the $\mathrm{PaO}_{2} / \mathrm{FiO}_{2}$ is assigned a weighted score of 0 and 6 , with the lung donor scores ranging from 0 (ideal donor lungs) to 18 (worst possible donor lungs). The lung allocation score (LAS) of each recipient, indicative of the preoperative severity of the underlying lung diseases, was calculated retrospectively using the LAS calculator published on the OPTN website (https://optn.trans plant.hrsa.gov/resources/allocation-calculators/las-calcu lator/) in November, 2016. Chronic lung allograft dysfunction (CLAD)-free survival was defined as the time between the LTx and the date of disease onset. Overall survival was defined as the time between LTx and death. The study protocol (No. 1710-018) was approved by the institutional review board of Okayama University Hospital.

\section{Donor and recipient selection and the transplantation procedures}

Patients who require LTx are registered with the Japan Organ Transplantation Network. Because the LAS system has not yet been adopted in Japan, the allocation of organs from brain-dead donors is still based mainly on the waiting time. The transplant procedures have been described previously [7]. The graft ischemic time was defined as the ischemic time for the second transplanted lung in cases of bilateral LTx.

\section{Postoperative care}

The postoperative management of the LTx recipients, including the immunosuppressive therapy and prophylactic therapies against viral and fungal infections, has been described elsewhere [7, 8]. Patients were assigned PGD grades according to the definition of PGD proposed by the International Society for Heart and Lung Transplantation (ISHLT) [9]. All the LTx recipients received triple-immunosuppression therapy, consisting of tacrolimus or cyclosporine, mycophenolate mofetil (MMF), or azathioprine, and a corticosteroid. Basiliximab was given on postoperative days (PODs) 1 and 4 to patients identified as being at risk of renal dysfunction. Acute rejection was treated by bolus intravenous corticosteroid administration for 3 days. CLAD was diagnosed based on the classification system proposed by the ISHLT [10].

\section{Statistical analysis}

All statistical analyses were performed using the GraphPad Prism5 software (San Diego, CA, USA). Normally distributed continuous variables were expressed as means \pm standard deviations. Bivariate comparison of continuous variables was performed by Student's $t$ test. Associations between categorical variables were tested by Fisher's exact test. The postoperative survival rate was analyzed by the Kaplan-Meier method, with the log-rank test used to determine the significance of differences between the groups. Differences were considered significant at $p<0.05$. The results were analyzed as of July 31, 2017.

\section{Results}

\section{Donor characteristics}

Table 1 summarizes the donor characteristics. The duration of mechanical ventilation of the donors from both groups ranged from 1 to 326 days, with the median duration being 3 days in the ST group and 8.5 days in the LT group (Fig. 1). Despite the difference in the duration of ventilation, the lung donor scores were similar in the two groups, except that among the five variables forming the basis for the lung donor score, the score for secretions was significantly higher in the LT group than in the ST group ( $p=0.021)$. Table 2 shows the distribution of scores for the variables comprising the lung donor score. There were no significant differences in the distribution of items outside the standard acceptability criteria, such as $\mathrm{PaO} 2 / \mathrm{FiO} 2<300 \mathrm{mmHg}$, age over 55 years, or history of smoking $>20$ pack-years, between the two groups.

\section{Recipient characteristics}

As shown in Table 3, the preoperative characteristics of the recipients were similar between the LT group and the ST group. Of note, the mean waiting time for LTx in both 
Table 1 Donor characteristics

\begin{tabular}{|c|c|c|c|}
\hline Variables & Short-term group $(n=31)$ & Long-term group $(n=50)$ & $P$ value \\
\hline Age (years) & $47.2 \pm 14.1$ & $42.3 \pm 15.8$ & 0.16 \\
\hline$<18$ years & 0 & $4(8 \%)$ & 0.29 \\
\hline \multicolumn{4}{|l|}{ Gender } \\
\hline Male & $16(51.6 \%)$ & $31(62.0 \%)$ & \multirow[t]{2}{*}{0.37} \\
\hline Female & $15(48.4 \%)$ & $19(38.0 \%)$ & \\
\hline Body mass index $\left(\mathrm{kg} / \mathrm{m}^{2}\right)$ & $23.0 \pm 5.4$ & $23.2 \pm 5.5$ & 0.87 \\
\hline \multicolumn{4}{|l|}{ Smoking history } \\
\hline Yes & $16(51.6 \%)$ & $27(54.0 \%)$ & \multirow[t]{2}{*}{1.00} \\
\hline No & $15(48.4 \%)$ & $23(46.0 \%)$ & \\
\hline \multicolumn{4}{|l|}{ Cause of death } \\
\hline Intracranical bleeding & $19(61.3 \%)$ & $28(56.0 \%)$ & 0.82 \\
\hline Hypoxic brain injury & $4(12.9 \%)$ & $11(22.0 \%)$ & 0.39 \\
\hline Traumatic brain injury & $6(19.4 \%)$ & $8(16.0 \%)$ & 0.77 \\
\hline Cerebro-vascular accident & $2(6.5 \%)$ & $2(4.0 \%)$ & 0.63 \\
\hline Other & 0 & $1(2.0 \%)$ & 1.00 \\
\hline $\begin{array}{l}\text { Median duration of mechanical } \\
\text { ventilation (days) }\end{array}$ & 3 (range, $1-4$ ) & 8.5 (range, 5-326) & \\
\hline \multicolumn{4}{|c|}{ Chest-computed tomographic assessment } \\
\hline Yes & $23(74.2 \%)$ & $36(72.0 \%)$ & \multirow[t]{2}{*}{1.00} \\
\hline No & $8(25.8 \%)$ & $14(28.0 \%)$ & \\
\hline $\mathrm{PaO}_{2} / \mathrm{FiO}_{2}$ & $414.1 \pm 99.6$ & $434.0 \pm 117.6$ & 0.44 \\
\hline Lung donor score & $6.2 \pm 2.9$ & $5.7 \pm 3.1$ & 0.52 \\
\hline Age score & $1.2 \pm 1.2$ & $0.8 \pm 1.1$ & 0.16 \\
\hline Smoking history score & $0.4 \pm 0.6$ & $0.3 \pm 0.6$ & 0.41 \\
\hline Chest X-ray score & $1.4 \pm 0.9$ & $1.3 \pm 1.0$ & 0.95 \\
\hline Secretions score & $1.0 \pm 0.5$ & $1.3 \pm 0.5$ & 0.021 \\
\hline $\mathrm{PaO}_{2} / \mathrm{FiO}_{2}$ score & $2.2 \pm 2.2$ & $2.0 \pm 2.3$ & 0.66 \\
\hline Ex vivo lung perfusion use & 0 & $1(2.0 \%)$ & 1.00 \\
\hline
\end{tabular}

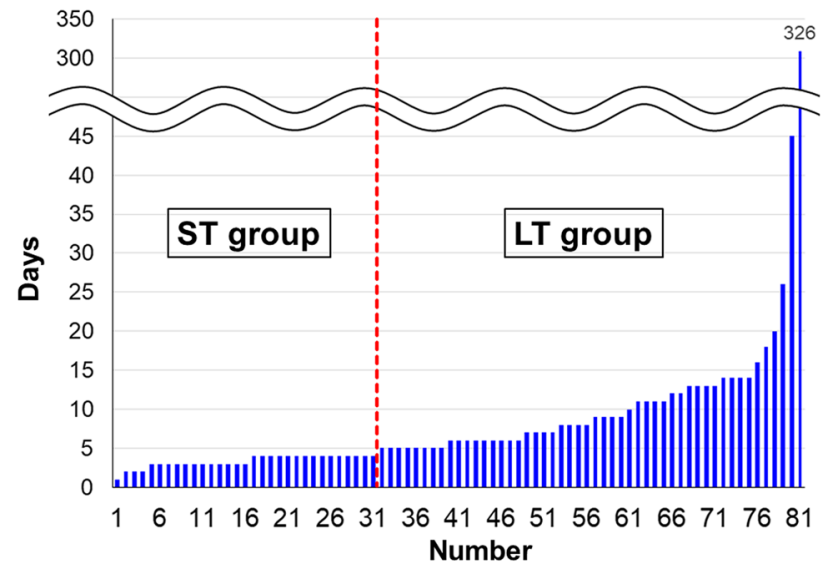

Fig. 1 Distribution of the duration of mechanical ventilation in the brain-dead donors. The duration of ventilation ranged from 1 to 326 days in 81 donors ( $<5$ days in 31 cases and $\geq 5$ days in 50 cases)

groups was about 2 years. Table 4 summarizes the postoperative outcomes of the recipients, with no remarkable differences observed between the groups. Any length of mechanical ventilation led to CLAD (Fig. 2). The CLADfree survival rate in the LT group was nearly the same as that in the ST group (5-year survival rate, $57.0 \%$ vs. $57.5 \%$ ) (Fig. 3). The overall survival rate in the LT group was also comparable to that in the ST group (5-year survival rate, $66.6 \%$ vs. $75.2 \%$ ) (Fig. 4 ).

\section{Discussion}

In this study, the outcomes of LTx from donors ventilated for prolonged periods ( $\geq 5$ days) were equivalent to those of LTx from donors ventilated for a short period ( $<5$ days). This suggests that the inclusion of donors ventilated for more than 5 days could expand the donor pool for LTx. Thus, our results indicate that prolonged mechanical ventilation of donors is not a contraindication per se to donation, and that the utilization of the donor lungs should be based more on a comprehensive assessment of the donor lung condition; for example, by evaluating the donor lung score. 
Table 2 Distribution of the lung donor score

\begin{tabular}{|c|c|c|c|c|c|}
\hline Category & Stratification & Score & $\begin{array}{l}\text { Short-term group } \\
(n=31)\end{array}$ & $\begin{array}{l}\text { Long-term group } \\
(n=50)\end{array}$ & $P$ value \\
\hline \multirow[t]{4}{*}{ Age (years) } & $<45$ & 0 & $13(41.9 \%)$ & $27(54.0 \%)$ & 0.36 \\
\hline & $45-54$ & 1 & $6(19.4 \%)$ & $13(26.0 \%)$ & 0.59 \\
\hline & $55-59$ & 2 & $6(19.4 \%)$ & $3(6.0 \%)$ & 0.079 \\
\hline & $\geq 60$ & 3 & $6(19.4 \%)$ & $7(14.0 \%)$ & 0.55 \\
\hline \multirow{4}{*}{$\begin{array}{l}\text { Smoking history } \\
\text { (pack-years) }\end{array}$} & $<20$ & 0 & $20(64.5 \%)$ & $39(78.0 \%)$ & 0.21 \\
\hline & $20-39$ & 1 & $9(29.0 \%)$ & $8(16.0 \%)$ & 0.17 \\
\hline & $40-59$ & 2 & $2(6.5 \%)$ & $2(4.0 \%)$ & 0.63 \\
\hline & $\geq 60$ & 3 & 0 & $1(2.0 \%)$ & 1.00 \\
\hline \multirow[t]{4}{*}{ Chest X-ray } & Clear & 0 & $7(22.6 \%)$ & $13(26.0 \%)$ & 0.80 \\
\hline & Minor & 1 & $8(25.8 \%)$ & $15(30.0 \%)$ & 0.80 \\
\hline & Opacity $\leq 1$ lobe & 2 & $14(45.2 \%)$ & $14(28.0 \%)$ & 0.15 \\
\hline & Opacity $>1$ lobe & 3 & $2(6.5 \%)$ & $8(16.0 \%)$ & 0.30 \\
\hline \multirow[t]{4}{*}{ Secretions } & None & 0 & $3(9.7 \%)$ & $1(2.0 \%)$ & 0.15 \\
\hline & Minor & 1 & $24(77.4 \%)$ & $33(66.0 \%)$ & 0.32 \\
\hline & Moderate & 2 & $4(12.9 \%)$ & $16(32.0 \%)$ & 0.066 \\
\hline & Major & 3 & 0 & 0 & - \\
\hline \multirow[t]{4}{*}{$\mathrm{PaO}_{2} / \mathrm{FiO}_{2}$} & $>450$ & 0 & $12(38.7 \%)$ & $28(56.0 \%)$ & 0.17 \\
\hline & $351-450$ & 2 & $9(29.0 \%)$ & $9(18.0 \%)$ & 0.28 \\
\hline & $301-350$ & 4 & $5(16.1 \%)$ & $3(6.0 \%)$ & 0.25 \\
\hline & $\leq 300$ & 6 & $5(16.1 \%)$ & $10(10.0 \%)$ & 0.77 \\
\hline
\end{tabular}

\begin{tabular}{|c|c|c|c|}
\hline Variables & Short-term group $(n=31)$ & Long-term group $(n=50)$ & $P$ value \\
\hline Age at lung transplantation (years) & $40.3 \pm 13.7$ & $37.5 \pm 15.1$ & 0.42 \\
\hline \multicolumn{4}{|l|}{ Gender } \\
\hline Male & $13(41.9 \%)$ & $25(50.0 \%)$ & \multirow[t]{2}{*}{0.50} \\
\hline Female & $18(58.1 \%)$ & $25(50.0 \%)$ & \\
\hline \multicolumn{4}{|l|}{ Diagnosis } \\
\hline Interstitial pneumonia & $11(35.5 \%)$ & $14(28.0 \%)$ & 0.62 \\
\hline Pulmonary hypertension & $5(16.1 \%)$ & $9(18.0 \%)$ & 1.00 \\
\hline Pulmonary graft versus host disease & $3(9.7 \%)$ & $8(16.0 \%)$ & 0.52 \\
\hline Bronchiectasis & $1(3.2 \%)$ & $6(12.0 \%)$ & 0.24 \\
\hline Emphysema & $2(6.5 \%)$ & $5(10.0 \%)$ & 0.70 \\
\hline Lymphangioleiomyomatosis & $4(12.9 \%)$ & $4(8.0 \%)$ & 0.47 \\
\hline Diffuse panbronchiolitis & $2(6.5 \%)$ & $2(4.0 \%)$ & 0.63 \\
\hline Chronic lung allograft dysfunction & $1(3.2 \%)$ & $2(4.0 \%)$ & 1.00 \\
\hline Other diseases & $2(6.5 \%)$ & 0 & 0.14 \\
\hline Body mass index $\left(\mathrm{kg} / \mathrm{m}^{2}\right)$ & $18.6 \pm 4.8$ & $19.2 \pm 3.9$ & 0.60 \\
\hline Lung allocation score & $38.6 \pm 5.5$ & $38.4 \pm 6.7$ & 0.59 \\
\hline Waiting time (days) & $721.1 \pm 497.3$ & $835.6 \pm 747.3$ & 0.46 \\
\hline \multicolumn{4}{|l|}{ Preoperative condition } \\
\hline Tracheostomy & $1(3.2 \%)$ & $4(8.0 \%)$ & 0.64 \\
\hline Ventilator & $1(3.2 \%)$ & $3(6.0 \%)$ & 1.00 \\
\hline \multicolumn{4}{|l|}{ Lung transplant procedure } \\
\hline Bilateral & $22(71.0 \%)$ & $38(76.0 \%)$ & \multirow[t]{2}{*}{0.61} \\
\hline Single & $9(29.0 \%)$ & $12(24.0 \%)$ & \\
\hline Cardiopulmonary bypass use & $24(77.4 \%)$ & $36(72.0 \%)$ & 0.79 \\
\hline Total ischemic time (min) & $479.1 \pm 118.7$ & $515.1 \pm 131.0$ & 0.22 \\
\hline
\end{tabular}

Table 3 Recipient characteristics 
Table 4 Postoperative results

\begin{tabular}{|c|c|c|c|}
\hline Variables & Short-term group $(n=31)$ & Long-term group $(n=50)$ & $P$ value \\
\hline Primary graft dysfunction of grade 2 or 3 by 48 and 72 h after LTx & $24(38.7 \%)$ & $40(40.0 \%)$ & 1.00 \\
\hline Extracorporeal membrane oxygenation & $3(9.7 \%)$ & $2(4.0 \%)$ & 0.37 \\
\hline Tracheostomy & $12(38.7 \%)$ & $15(30.0 \%)$ & 0.47 \\
\hline Ventilator support (days) & $12.9 \pm 15.5$ & $18.0 \pm 35.5$ & 0.46 \\
\hline Basiliximab usage & $11(35.5 \%)$ & $18(36.0 \%)$ & 1.00 \\
\hline Acute rejection episodes & $0.55 \pm 0.80$ & $0.36 \pm 0.66$ & 0.26 \\
\hline Antibody-mediated rejection & $3(9.7 \%)$ & $2(4.0 \%)$ & 0.37 \\
\hline Postoperative pneumonia within 30 days & $9(29.0 \%)$ & $21(42.0 \%)$ & 0.34 \\
\hline Bronchial complication per anastomosis & $3 / 53(5.7 \%)$ & $10 / 88(11.4 \%)$ & 0.37 \\
\hline 30-day mortality & $1(3.2 \%)$ & $1(2.0 \%)$ & 1.00 \\
\hline FEV1, 2 years after $\mathrm{LT} \times(\mathrm{L})$ & $1.83 \pm 0.79$ & $1.87 \pm 0.65$ & 0.85 \\
\hline FVC, 2 years after $\mathrm{LT} \times(\mathrm{L})$ & $2.26 \pm 0.91$ & $2.20 \pm 0.72$ & 0.79 \\
\hline TLC, 2 years after $\mathrm{LT} \times(\mathrm{L})$ & $3.98 \pm 1.37$ & $3.82 \pm 0.88$ & 0.63 \\
\hline 6-min walk distance, 2 years after LTx (m) & $398.3 \pm 102.8$ & $419.2 \pm 119.2$ & 0.52 \\
\hline Lung infection between discharge and 2 years after LTx & $9(29.0 \%)$ & $17(34.0 \%)$ & 0.81 \\
\hline
\end{tabular}

FEV1 forced expiratory volume in $1 \mathrm{~s}, F V C$ forced vital capacity, $L T x$ lung transplantation, $T L C$ total lung capacity

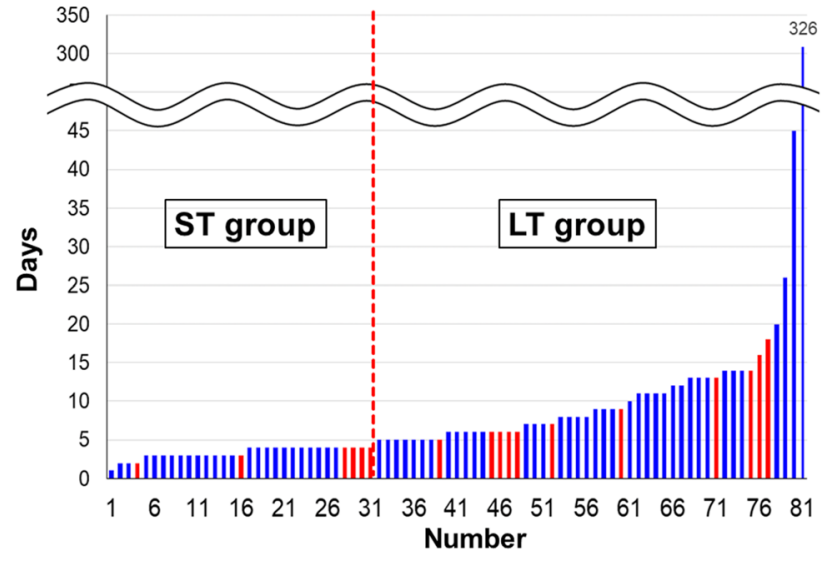

Fig. 2 Distribution of the duration of mechanical ventilation in the brain-dead donors and patients with chronic lung allograft dysfunction. The red bar indicates a case of developing chronic lung allograft dysfunction

Despite the prolonged ventilation of donors in our LT group, these donors showed adequate lung quality for LTx in terms of the long-term postoperative outcomes. Generally, lung transplant centers are reluctant to accept braindead donors who have been on prolonged ventilation. In addition to neurogenic pulmonary edema or acute lung injury induced by hemodynamic, neurogenic, and hormonal changes after brainstem death [11], prolonged ventilation in brain-dead donors also frequently causes atelectasis and ventilator-associated pneumonia. Accordingly, early lung retrieval from brain-dead donors is considered important for securing donor lung quality [12]. Thus, it has been recommended that brain-dead donors mechanically ventilated for

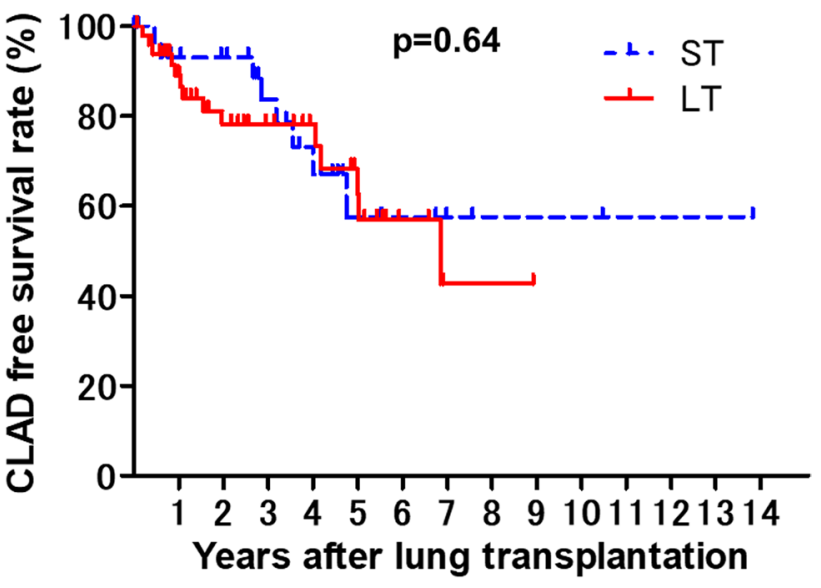

Fig. 3 Chronic lung allograft dysfunction (CLAD)-free survival after lung transplantation. The 5-year CLAD-free survival rate in the long-term (LT) group was similar to that in the short-term (ST) group $(57.0 \%$ vs. $57.5 \%)$. There was no significant difference in the CLADfree survival rate between the groups $(p=0.64)$

more than 5 days be declined as organ donors for LTx [2, 3, 13]. However, the aggressive donor management reported recently by some centers [14-17] could help to maintain the condition of donor lungs even after prolonged ventilation. In fact, in this study, the lung quality, as evaluated by the lung donor score, was maintained even in donors who had been on mechanical ventilation for prolonged periods under aggressive donor management, which is practiced nationwide in Japan $[16,17]$. To maintain the integrity of the limited number of donor lungs in Japan, special transplant management doctors have been sent to donor hospitals to assess the lung function and support the provision of intensive care 


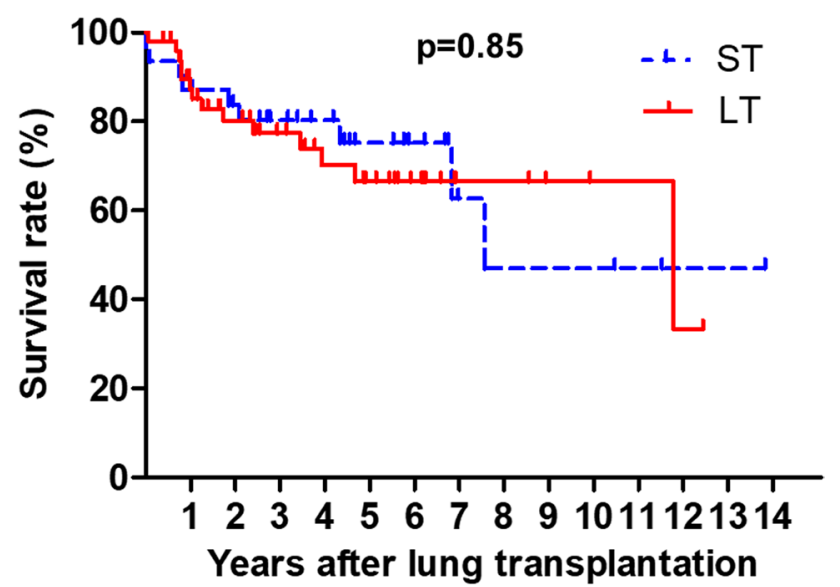

Fig. 4 Overall survival after lung transplantation. The 5-year survival rate in the long-term (LT) group was comparable to that in the shortterm (ST) group ( $66.6 \%$ vs. $75.2 \%)$, and there was no significant difference in the overall survival rate between the groups $(p=0.85)$

for the donors. Through this system, ECD lungs ventilated for prolonged periods have been used aggressively to maximize the limited organ transplant opportunities in Japan. The fact that the rate of chest CT was more than $70.0 \%$ in both groups also indicates that precise assessment using chest $\mathrm{CT}$ is appropriate to evaluate the lungs of potential donors ventilated for prolonged periods. Moreover, while lung donors mechanically ventilated for a short period could be developing pneumonia at the time of organ procurement, lung donors mechanically ventilated for a prolonged period would have already developed pneumonia prior to procurement, which could be treated with adequate antibiotic use or be declined for donation if the treatment proves ineffective.

The recipient characteristics were similar in the two groups. The waiting time for cadaveric LTx was about 2 years in this study, consistent with the national average in Japan, because of the extreme donor organ shortage. In this situation, living-donor lobar LTx is still a realistic option for urgent LTx in Japan; therefore, recipients with high LAS tend to receive living-donor lobar LTx at our hospital [7]. On the other hand, cardiopulmonary bypass was used for most of the bilateral LTxs, to prevent uncontrolled reperfusion of the first implanted lung and to utilize its advantage of providing intraoperative hemodynamic stability. This is because the donor lungs in this study were marginal for LTx, with an average lung donor score of close to 7 , which is the upper limit for lung utilization, as reported previously [6].

Prolonged mechanical ventilation of the lung donors had no negative impact on the postoperative outcomes of the LTx recipients in this study. We previously reported the negative impact of prolonged mechanical ventilation in the development of PGD after LTx, including cadaveric LTx and living-donor lobar LTx; however, we did not find a significant difference in the PGD grade distribution in the exclusively cadaveric LTx in this study [5]. Despite the significantly larger amount of secretions in the donors of the LT group, there was no difference in the incidence of pneumonia in the recipients between the two groups, although donor-to-host transmission of infection has been shown to occur frequently after LTx [4]. Moreover, prolonged positive-pressure mechanical ventilation may potentially cause emphysematous changes in the donor lungs, resulting in the early development of CLAD in recipients; however, there was no significant difference in the incidence of CLAD between the groups in this study. Thus, the overall use of lungs from donors on mechanical ventilation for prolonged periods had no significant effect on the overall survival rate. Our results provide encouragement for the use of ECD lungs for LTx, even after prolonged mechanical ventilation, if the lung quality is favorable for LTx.

Compared with other countries, the number of brain-dead organ donations in Japan is still low, despite the modification of the Organ Transplant Law in 2010. The organ donation system and the social background contributed to the prolonged ventilation of the donors in this study. In Japan, unlike in many other countries, there is no legislation related to potential donor referral, and the option to retrieve organs from brain-dead patients is a decision made by the physicians in charge [18]. Consequently, it takes a longer for informed consent for organ donation to be obtained after identification of a potential donor, leading to prolonged ventilation of the donor lung. Furthermore, the pre-retrieval time tends to be longer for pediatric donors than for adult donors. Since there have been only 12 cases of donation from subjects $<15$ years of age between the first donation from a brain-dead donor in February, 1999 and 2016 in Japan, it generally takes a long time to confirm the family's consent for pediatric donors. In fact, all four pediatric donors were included in the LT group in this study.

Our study had several limitations. First, it was a retrospective observational study conducted at a single transplant center. Second, the number of recipients enrolled was small because the number of donations from brain-dead donors is still limited in Japan. Third, the follow-up period was still intermediate in some cases, and longer-term follow-up is required for more reliable evaluation.

In conclusion, LTx from donors on mechanical ventilation for prolonged periods ( $\geq 5$ days) yielded favorable outcomes, comparable to those of LTx from donors on mechanical ventilation for short periods ( $<5$ days). Our results suggest that the utilization, under aggressive donor management, of selected donors on mechanical ventilation for prolonged periods, considered as marginal donors, could be a feasible strategy to expand the donor pool for LTx, and should not always be precluded if careful selection and evaluation is conducted. 


\section{Compliance with ethical standards}

Conflict of interest Seiichiro Sugimoto and his co-authors have no conflicts of interest.

\section{References}

1. Sommer W, Kuhn C, Tudorache I, Avsar M, Gottlieb J, Boethig D, et al. Extended criteria donor lungs and clinical outcome: results of an alternative allocation algorithm. J Heart Lung Transplant. 2013;32:1065-72.

2. Botha P, Archer L, Anderson RL, Lordan J, Dark JH, Corris PA, et al. Pseudomonas aeruginosa colonization of the allograft after lung transplantation and the risk of bronchiolitis obliterans syndrome. Transplantation. 2008;85:771-4.

3. Bansal R, Esan A, Hess D, Angel LF, Levine SM, George T, et al. Mechanical ventilatory support in potential lung donor patients. Chest. 2014;146:220-7.

4. Ruiz I, Gavalda J, Monforte V, Len O, Roman A, Bravo C, et al. Donor-to-host transmission of bacterial and fungal infections in lung transplantation. Am J Transplant. 2006;6:178-82.

5. Tanaka S, Miyoshi K, Kurosaki T, Otani S, Sugimoto S, Yamane $\mathrm{M}$, et al. Refinement of lung donor scoring system with consideration for negative impact of prolonged donor intubation time. $\mathrm{J}$ Heart Lung Transplant. 2016;35:369.

6. Oto T, Levvey BJ, Whitford H, Griffiths AP, Kotsimbos T, Williams TJ, et al. Feasibility and utility of a lung donor score: correlation with early post-transplant outcomes. Ann Thorac Surg. 2007;83:257-63.

7. Sugimoto S, Yamane M, Otani S, Kurosaki T, Okahara S, Hikasa $\mathrm{Y}$, et al. Airway complications have a greater impact on the outcomes of living-donor lobar lung transplantation recipients than cadaveric lung transplantation recipients. Surg Today. 2018. https ://doi.org/10.1007/s00595-018-1663-6.

8. Hirano Y, Sugimoto S, Mano T, Kurosaki T, Miyoshi K, Otani $\mathrm{S}$, et al. Prolonged administration of twice-daily bolus intravenous tacrolimus in the early phase after lung transplantation. Ann Transplant. 2017;22:484-92.
9. Christie JD, Carby M, Bag R, Corris P, Hertz M, Weill D. Report of the ISHLT Working Group on primary lung graft dysfunction part II: definition. A consensus statement of the International Society for Heart and Lung Transplantation. J Heart Lung Transplant. 2005;24:1454-59.

10. Verleden GM, Raghu G, Meyer KC, Glanville AR, Corris P. A new classification system for chronic lung allograft dysfunction. J Heart Lung Transplant. 2014;33:127-33.

11. Avlonitis VS, Fisher AJ, Kirby JA, Dark JH. Pulmonary Transplantation: the role of brain death in donor lung injury. Transplantation. 2003;75:1928-33.

12. Moreno P, Alvarez A, Illana J, Espinosa D, Baamonde C, Cerezo $\mathrm{F}$, et al. Early lung retrieval from traumatic brain-dead donors does not compromise outcomes following lung transplantation. Eur J Cardiothorac Surg. 2013;43:e190-7.

13. Mascia L, Pasero D, Slutsky AS, Arguis MJ, Berardino M, Grasso $\mathrm{S}$, et al. Effect of a lung protective strategy for organ donors on eligibility and availability of lungs for transplantation: a randomized controlled trial. JAMA. 2010;304:2620-7.

14. Angel LF, Levine DJ, Restrepo MI, Johnson S, Sako E, Carpenter A, et al. Impact of a lung transplantation donor-management protocol on lung donation and recipient outcomes. Am J Respir Crit Care Med. 2006;174:710-6.

15. Minambres E, Coll E, Duerto J, Suberviola B, Mons R, Cifrian $\mathrm{JM}$, et al. Effect of an intensive lung donor-management protocol on lung transplantation outcomes. J Heart Lung Transplant. 2014;33:178-84.

16. Fukushima N, Ono M, Saito S, Saiki Y, Kubota S, Tanoue Y, et al. Japanese strategies to maximize heart and lung availabilities: experience from 100 consecutive brain-dead donors. Transplant Proc. 2013;45:2871-4.

17. Hoshikawa Y, Okada Y, Ashikari J, Matsuda Y, Niikawa H, Noda $\mathrm{M}$, et al. Medical consultant system for improving lung transplantation opportunities and outcomes in Japan. Transplant Proc. 2015;47:746-50.

18. Soyama A, Eguchi S. The current status and future perspectives of organ donation in Japan: learning from the systems in other countries. Surg Today. 2016;46:387-92. 